\title{
Pediatric Liquid Dosage Form
}

National Cancer Institute

\section{Source}

National Cancer Institute. Pediatric Liquid Dosage Form. NCI Thesaurus. Code C69042.

A solution or suspension intended for use in children. 